\title{
LAUREATES OF THE HISTORY OF ANESTHESIA, 2000
}

I N 1992 the Wood Library-Museum Board of Trustees voted to establish an international Laureate of the History of Anesthesia program to promote understanding of the importance of the heritage of anesthesia and to honour, every four years, an outstanding contributor to this heritage. The first Laureate of the History of Anesthesia, in 1996, was Dr. Gwenifer Wilson of Sydney, Australia. In 2000 the WLM Laureate Committee faced a tie so irreconcilable as to necessitate naming both of two equally meritorious candidates as Laureates: Dr. Thomas Boulton of Great Britain and Dr. Norman Bergman of the United States.

Thomas B. Boulton oBE TD MA MB BCHIR FRCA FDSRCS DA Dr. Boulton was born in 1925 in County Durham, England, graduated from Cambridge University and from St. Bartholomew's Hospital Medical College before entering a career that has made him one of the most eminent anesthetists in the United Kingdom. He is past president of the Association of Anaesthetists of Great Britain and Ireland, and a former Editor of Anaesthesia. He also led other anesthesia-related organizations, and is a prolific author and a much sought after lecturer.

Dr. Boulton's historical contributions are legion. He has been the editor of the Classical Files, a prominent feature of the Survey of Anesthesiology, since 1983. He advocated and helped found the History of Anaesthesia Society in the United Kingdom, and subsequently became its president in 1988. For many years, he was the Hon. Archivist of the Association of Anaesthetists of Great Britain and Ireland. Known for his historical scholarship, Dr. Boulton chaired the 2nd International Symposium for the History of Anaesthesia in London in 1987, and was the co-editor of its proceedings, titled The History of Anaesthesia, published in 1988 by the Royal Society of Medicine. He delivered the Lewis H. Wright Memorial Lecture of the Wood Library-
Nicholas M. Greene MD
Museum of Anesthesiology in 1990. Dr. Boulton considers his 1999 book, The Association of Anaesthetists of Great Britain and Ireland, 1932-1992, and the Development of the Specialty of Anaesthesia, the most important singular contribution to the history of anesthesia he has ever made.

Norman A. Bergman BA MD FRCA

Born in 1926 in Seattle, Washington, Dr. Bergman received his B.A. degree from Reed College in Portland, Oregon in 1949 and his M.D. degree from the University of Oregon in 1951. After residency in anesthesiology at Columbia Presbyterian Hospital in New York City (1951-54), he started working his way up the academic ladder at Columbia University (195458 ), at the University of Utah (1958-70) and finally to becoming Professor and Chair at the Department of Anesthesiology from 1970 to 1989 . His research interest throughout these two decades included many appointments as Visiting Research Associate in Great Britain in research centres such as Northwick Park, the Royal College of Surgeons of England and, also in London, Hammer-Smith Hospital and Postgraduate Medical School, as well as at the Karolinska Sjukhuset in Stockholm. The research experiences in the physiology of respiration in these institutions when added to similar research in pulmonary physiology at his own department in Portand soon made him internationally recognized and respected as an expert in this area of physiology. His experiences in England also formed the foundation for work that came to make his name famous, the publication of magnus opus: Genesis of Surgical Anesthesia, a masterful and definitive review of foundations upon which anesthesia was based before the introduction of ether anesthesia in 1846.

Lamentably Dr. Bergman died in the interval between his election as Laureate in 1999 and October 2000 when his investiture as Laureate was to take place. His investiture will, however, still be held in

Address correspondence to: Wood Library-Museum of Anesthesiology, 520 N. Northwest Highway, Park Ridge, Illinois 60068-2573 Phone: 847-825-5586; Fax: 847-825-1592; E-mail: wlm@ASAhq.org 
October 2000 during the annual meeting of the American Society of Anesthesiologists with presentation of his Laureate medal, his Laureate scroll, and his honorarium to his family. 